\title{
公共建筑设计中人性化设计的策略研究
}

李晓宇 ${ }^{1}$ 刘玉诚 $^{2}$

1 中国移动通信集团设计院有限公司河北分公司 2 河北九易庄宸科技股份有限公司

DOI:10.32629/ems.v2i1.576

[摘要] 随着建筑行业的发展迅速,人们对建筑设计提出了更高的要求。所以,建筑设计必须紧跟时代的发展,在建筑 设计中除了要满足人们对建筑功能多样化要求,还应充分考虑建筑舒适性、节能环保等因素,并且在建筑设计中要融 入情感, 从而实现建筑人性化设计。建筑的目的就是满足人们对空间使用的需求,因而在此背景下,为了加快推进现代 建筑行业的发展和进程,设计师在实际设计过程中应该将人性化设计理念始终贯通于公共建筑设计中,增强人与公共 建筑空间的密切程度,提升整体设计功能。

[关键词] 公共建筑; 人性化设计理念;研究

\section{1 建筑人性化设计概述}

\section{1 建筑设计的含义}

建筑设计是指在建设建筑物开始之前, 设计人员需 要根据工程需要, 认真的规划和设计建筑工程的过程。设 计人员应该全面考虑各种可能性，在设计图纸中明确标 出, 施工的步骤、施工技术与施工方法、施工材料。设计图 纸不仅是施工过程中施工与采购之间进行合作的重要 依据, 也是确定工程投资方案的依据。为了确保工程的施 工过程安全有序的进行, 在整个工程开始之前, 都必须要 进行紧密的考量和计划, 以此来进行方案预定, 避免出现 较大误差。

\section{2 建筑设计的核心理念}

建筑设计的不仅是要建设优美精致的建筑, 主要是 要建设安全的建筑。建筑设计的核心, 就是找到最佳的解 决方法来处理整个施工过程中所遇到的任何情况。在长 期的积累和实践中, 建筑师已经可以以图纸的方式来表 现和解决问题, 通过这样直观的方式, 可以与其他建筑师 交流、讨论,共同努力,力争将矛盾解决。为了将方案做的 更加完美和安全, 也需要在一个工程中设计出多个方案, 最后进行比较,选用最成熟的方案。

\section{3 建筑设计中环境设计的步骤}

建筑设计中环境的设计首先要对建筑物所处的位 置和周围的环境进行勘探, 外部环境有哪些特点, 都需要 进行实地了解, 再选择方便居民生活, 提高生活水平并且 适合当地文化特色的地点。建筑物的建设必须要坚持以 使用者的角度和场地来进行设计, 才能体现人性化设计 理念。在进行建筑设计和构造之时, 能够充分满足人们的 使用需求,从心理到生理,都能够得到享受。

\section{2 人性化的设计理念}

建筑设计中的人性化设计,不仅是指某一个区域, 而 是贯穿于整个建筑设计的领域中。在设计时, 应该根据人 的心理情况、思维模式、行为习惯、人体结构等各个方面
来考量。以原本的设计为基础,将整体设计进行优化,让 使用者从视觉和使用感受上更加便捷和舒服, 这就是人 性化设计的体现。科学技术可以让建筑的功能设计优良, 是整个建筑的基础。艺术的运用可以让建筑富有美感, 使 整个建筑充满魅力与情趣。可用性设计是人性化设计的 一个概念, 都是坚持以人为本的设计理念, 来满足用户的 切实需求。建筑师在设计任何建筑时都不能忽视和丢失 人性化设计, 在设计中人性化设计要渗透于建筑的每个 环节及细节中。在进行建筑设计之时,往往一个小小的创 意, 一点小小的改善, 都会给用户的生活带来极大的方 便。由此可见,人性化的设计理念, 必将是未来设计领域 的大势所趋。风格设计也是目前建筑设计中需要考虑的 关键部分,在不同的城市和地区之中,都有着形色各异的 文化内涵和文化特色, 因此, 在进行建筑设计之时, 设计师 需要用自己的眼睛和独特的视角, 感知和发现这些微妙 的文化因素。在符合风格的同时,人性化设计中需要加人 人体工程学知识, 将其充分融人其设计中。其主要体现在 氛围的营造和结构之上,创造舒适和安逸的空间。

\section{3 公共建筑人性化设计的原则}

\section{1 舒适性原则}

人们一天中大多数时间都是在建筑中度过的, 建筑 中的任何变化都会对人们产生影响。现代建筑设计中建 筑的空间环境直接影响着建筑的舒适性。若是建筑的空 间环境无法带给人们舒适感, 就必定会出现枯燥乏味的 感觉, 从而给人们的身心健康带来不利影响, 所以, 现代建 筑人性化设计中应遵循舒适性原则。

\section{2 共享性原则}

共享性原则是指，在建筑中通过对空间的设计使人 们在建筑中能够形成一定的联系和交汇, 增加人与人之 间的社交机会。在建筑中, 人们的行为活动具有相互连 锁、随机发送的特点。在建筑中设计一个吸引、聚集人们 进行交互的场所非常重要, 能够为人们的社交活动提供 
机会。当有更大的社交机会提供给人们时,人们通常是非 常乐意参与到其中去的。

\section{3 复合性原则}

复合性原则是指,不同的元素之间进行有机结合,进 而就可以产生出全新的事物。复合性原则从东方哲学思 维来看,体现出了一种和哲学观。在现代建筑中,复合性 原则就是依据和的哲学观, 将建筑中的异质元素进行有 机结合,从而形成新的空间。因此,在现代建筑人性化设 计中遵循复合性原则, 能够更好的满足人们对建筑空间 进行多种活动的需求。

\section{4 诱发性原则}

诱发性原则是指,现代建筑中各种活动的发生手段。 在现代建筑中,不同的活动其目的性也不一致,一旦选择 了某一项必须性活动,这种活动具有极强的目的性, 受建 筑空间环境的影响较小。但是,若是选择自发性活动, 就 可以有多余的选择性, 而这就需要建筑中具有一个能够 吸引和聚集人进行活动的场所, 从而使得自发性活动变 为社会性活动,增加人们的社交机会。

\section{4 公共建筑人性化设计的分析}

4.1 融人情感思想与生活习惯, 提高建筑的舒适性

以往的建筑设计,由于过于追求功能、空间和效益, 使得建筑高大宽广, 却忽视了建筑的舒适性和是否能够 为人们的生活带来方便, 导致建筑设计缺乏人性化, 存在 一定缺陷。建筑设计是否具有合理性直接影响着建筑的 舒适性, 所以,为了解决这一建筑设计缺陷, 在现代建筑设 计中应融人人的情感思想与生活习惯, 提高建筑的舒适 性,从而提升建筑设计的市场性与价值性。

\section{2 关注细节}

事物的成功与失败在很大程度上取决于其细节, 在 建筑设计中也同样如此。所以, 在现代建筑人性化设计中 必须充分重视细节方面,这非常重要。例如: 若是人性化 设计的建筑为酒店, 在卫生间的设计上就特别需要关注 细节的设计。在设计酒店豪华客房的卫生间时，应考虑 干、湿分离,而且卫生间的使用面积应大于 8 平方米,酒 店普通客房的卫生间也应考虑干、湿分离,且卫生间的使 用面积应不小于 6 平方米。卫生间地面也需要进行防滑 设计,若是有浴缸则应该选择具有防滑性能的浴缸, 还应 在浴缸旁边设置紧急按钮或者警报器, 以防意外事故发 生。

\section{3 营造良好的环境氛围}

随着建筑空间环境的变化，人的行为方式也会发生 一定的变化, 若是建筑空间环境能够让人内心感受到愉 快、平静、哀伤等氛围,则表明该建筑空间环境具有精神 属性。营造良好的建筑环境在很大程度上取决于建筑设 计人员的能力。举例说明: 在进行公共图书馆建筑设计
时, 公共图书馆的环境性质是属于安静的场所, 是一个能 够让人放松心情,安静看书和学习的地方,所以,在设计时 必须突显出安静、平和的氛围,让人们一进人图书馆就可 以感受到安静、平和的氛围,从而第一时间就能静下心来 进行学习和看书。另外,颜色对于烘托环境也有着积极的 作用,通过环境颜色也能够对人们的心里产生影响。空间 环境为浅色会营造出一种空间比较突出、空旷的感觉,空 间环境为深色则会给人营造出一种空间形体后退的感 觉,空间环境为暖色的则会给人营造出一种浪漫、舒适的 感觉。此外,建筑的标志对于建筑的识别有着指导作用。 如果在建筑公共空间中没有标志的设计与应用, 就会出 现找不到地方的情况。随着中国建筑业的发展,公共空间 设计更加科学, 更具有美感, 不仅发挥其审美价值,且能充 分体现设计的功能价值,令人感到更加舒适。

\section{4 设置清晰合理流线}

在建筑人性化设计中,设置的流线是否清晰、合理非 常重要。例如,在设计公共医院建筑时,应清晰、合理的设 置好疾病咨询区、网络查询区、病人体息区等功能区域, 从而为人们看病就医提供便利, 充分体现建筑设计人性 化思想。

\section{5 重视生态环保、节能}

近年来,随着环保、节能理念的大力提倡与推广,生 态环保、节能理念深人人心, 所以在建筑设计中越来越重 视生态环保、节能,这就要求设计师在进行设计时充分考 虑建筑选址是否会对生态环境造成影响, 在设计中尽量 选用环保、节能材料,并积极应用环保、节能技术,从而为 人们创造一个更加舒适、健康、节能的生活环境。

\section{5 结束语}

综上可知,随着社会的快速发展,人们不仅追求物质 的享受,而且越来越重视精神方面的需求,公共建筑的人 性化设计,不仅满足了人们的精神需求, 更进一步提高了 人们的生活水平与质量, 还有助于促进我国建筑设计的 可持续发展。因此,为了营造一个健康、舒适的建筑环境。 要求设计师在进行公共建筑设计时, 把人性化设计始终 贯穿于整个设计中,且通过空间、材质、形象和环境来满 足人们的心理和生活需求, 以此来促使人们保持良好和 饱满的精神状态。

\section{[参考文献]}

[1]毛龙泉.大型公共建筑全寿命周期设计体系研究 [J].现代城市研究,2011(07):43+47.

[2]杨震.公共建筑的外部空间公共化融合设计初探 [J]. 山西建筑,2014(14): $1+3$.

[3]张树兰.拓扑建筑设计理念的应用与创新一试论 天津城市公共建筑新特点 [J]. 城市,2013(06):31+ 35 . 